\title{
Analysis of the Outer Surface Geometry on Drawn Tubes
}

Augustín Görög, Ingrid Görögová

Slovak University of Technology in Bratislava, Faculty of Material Science and Technology in Trnava, Institute of Production Technologies, J. Bottu 25, 91724 Trnava. Slovak Republic. E-mail: augustin.gorog@stuba.sk, ingrid.gorogova@stuba.sk

Technological conditions of tube drawing influence the properties of the resulting products. In addition to mechanical properties, they also affect the geometry of the drawing tube - macro geometry and microgeometry. The paper presents the results of measurements of macro geometry (roundness and cylindricity) and micro geometry (surface roughness) of the outer surface of the drawn tube. Tubes (STN 41 1353) were drawn through dies with different reduction angles $\left(6^{\circ}\right.$ and $\left.12^{\circ}\right)$. On used fixed mandrels were ground the straight and spiral grooves. The effect of these grooves and hence the deformation itself has also been manifested on the outer surface of the drawn tube. On the measured roundness profiles are significantly noticeable places where the land and the groove were when drawing. This effect can also be observed on the deteriorated measured values of roundness. On the measured values and roughness profiles of the outer surface of the drawn tube can also be observed the difference between land and grove.

Keywords: drawn tubes, roundness, cylindricity, surface roughness

\section{Introduction}

Tube drawing is a manufacturing process in which the cross-sectional area of a tube is reduced by pulling it through a drawing die. The drawing process [1] is one of the most used metal forming processes in the industrial field due to the versatility and good mechanical properties of the parts. [2] Tubes with spiral inner grooves are one of the important and useful components in the industry. The spiral grooves tubes are used in chemical plants, electric devices and so on. The representative tubes are shown in Fig. 1. The tubes with large inner grooves accelerate chemical reactions in the chemical industry, as the area of the tube's inner surface is large. They are used in petroleum refineries, for example. The tubes with small inner grooves enhance the heat change efficiency when they are mounted in air conditioners and refrigerators. The small grooves enlarge the contact area between the tube material and the fluid inside and affect the fluid flow for higher heat transfer. [3]

The spiral groove tubes are conventionally manufactured by different forming processes such as extrusion, pilger rolling, drawing with a spiral mandrel inside the tube. The authors [4] modified the traditional extrusion machine and can successfully extrude the trial extruded circular tube with many spiral projections on the inside wall. The extrusion was performed by the mandrel with set up number grooves. They discussed experimentally the influence of shape and the size on the trial extruded circular tube about processing conditions.

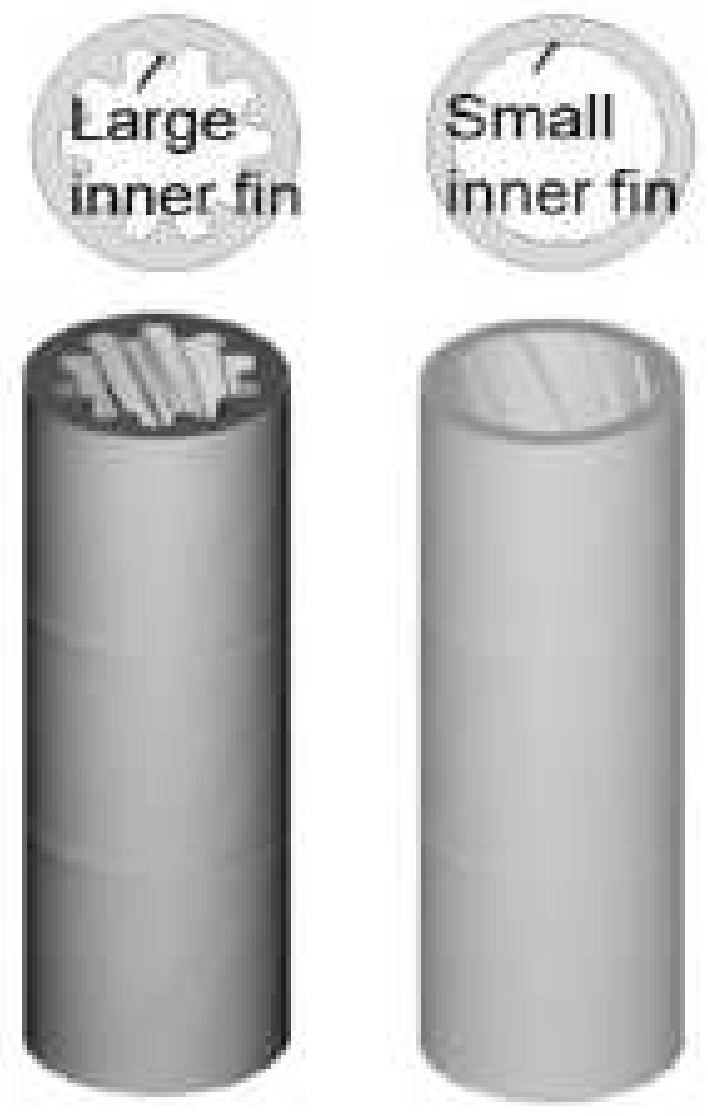

Fig. 1 Tubes with inner grooves

Kuboki et al [3] presented a new extrusion method for fabrication of a tube with spiral inner fins. The spiral fins are formed by utilizing the generation of spiral 
outer fins or grooves, which drive the metal to circumferentially move with twist deformation. The effect of the outer fins/grooves is examined for realizing the circumferential metal flow. The position of the mandrel has an ability to flexibly control the spiral angle. They state that this method would drastically enhance the productivity and reduce the manufacturing cost, as the tube would be manufactured directly from a billet through only one process. Gunasekera and Hoshino [5] described a new method for obtaining optimal die shape which produces minimal stress in the extrusion or the drawing of non-axisymmetric sections from round bar stock. In order to find the best geometry of die and plug to reduce the drawing force. Neves et al. [6] simulated the cold drawing of tubes with fixed plug by FEM with the commercial software MSC Superform. In [7], additional small grooves were newly carved on the surface of bearing for the acceleration of the spiral movement of the tube during extrusion. While relatively small projections were formed on the outer surface by the die-bearing grooves, large ones were formed on the inner surface by the mandrel grooves. With the increase of bearing length, the more the spirality was improved. Sufficient and stable spiral angles were achieved under appropriate conditions, compared to those extruded without die-bearing grooves. In this paper are presented the results of measurements of macro geometry (roundness and cylindricity) and microgeometry (surface roughness) of the outer surface of the drawn tube using fixed mandrels with the straight and spiral grooves.

\section{Methodology of experiment and materials}

The experimental work was made on unique instrumented equipment for experimental research of

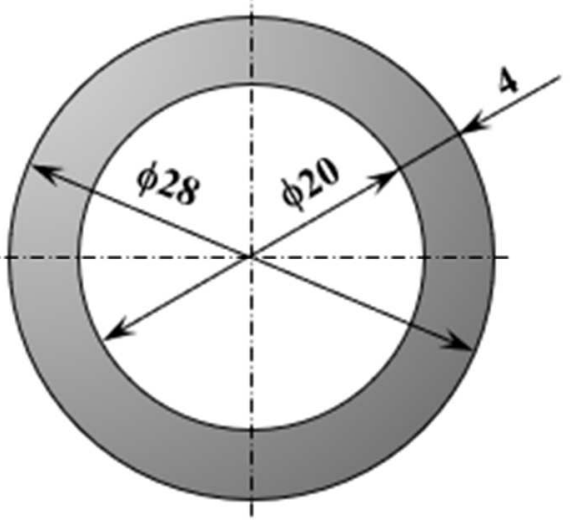

tube drawing. This equipment allows drawing the tubes on the tensile machine, while it is possible to measure and monitoring some technological parameters of the drawing process. On the mandrel rod was mounted the fixed mandrel. Fixed mandrels (sintered carbide) with straight and spiral grooves were used (Fig. 2). Spiral grooves had angle of $30^{\circ}$. The mandrel rod fastening allowed the mandrel to rotate about an axis during drawing (using a mandrel with spiral grooves). During drawing of the tube, the mandrel is drawn into the tube by frictional force. As a lubricant was used lubricant based on plant oil. [8]

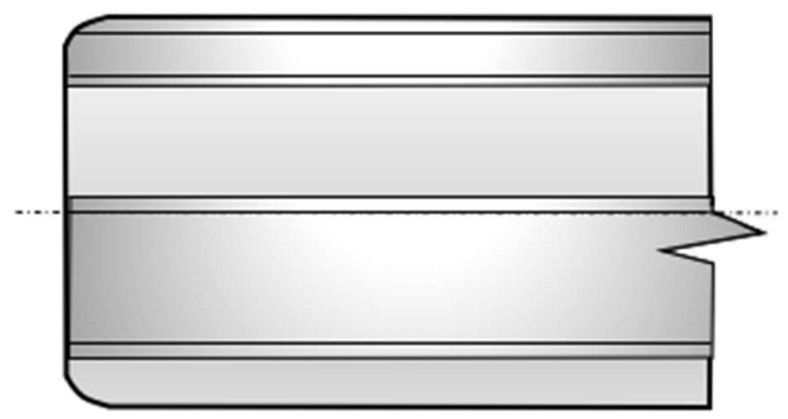

a) fixed mandrel with straight grooves

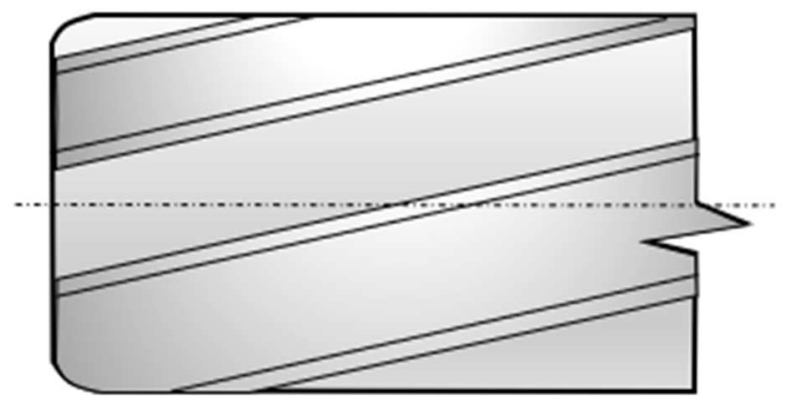

b) fixed mandrel with spiral grooves

Fig. 2The types of fixed mandrels [8]

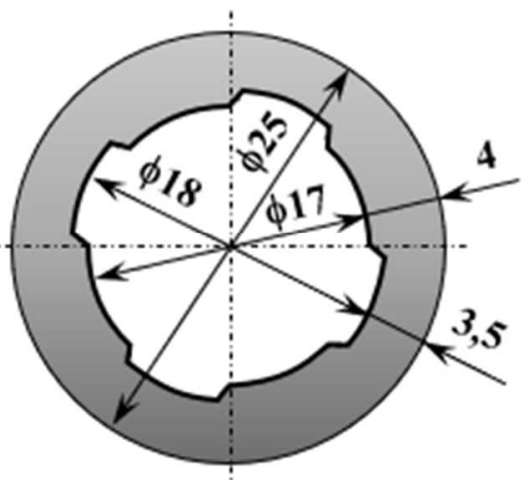

Fig. 3 Dimensional parameters of the tube before and after drawing

Construction steel STN 411353 was used as a tube material in the die drawing process. This is unalloyed structural fine grain steel having the following mechanical properties: $\operatorname{Re}=235 \mathrm{MPa}, \mathrm{Rm}=340-440 \mathrm{MPa}$, $\mathrm{A}=25 \%$. Just ductility $\mathrm{A}$ is the most important cha- racteristic of all metals. Ductility is the ability of a material to be drawn or plastically deformed without fracture. It is, therefore, an indication of how 'soft' or malleable the material is. [9] The properties of steel STN 411353 are mentioned in the tab. 1. 
Tab. 1 Chemical composition STN 411353 (in weight \%) [9]

\begin{tabular}{|c|c|c|c|c|}
\hline $\begin{array}{c}\text { Max. } \\
\text { value }\end{array}$ & 0.18 & 0.05 & 0.05 & 0.09 \\
\hline
\end{tabular}

The lands (wall thickness of $4 \mathrm{~mm}$ ) and grooves (wall thickness of $3.5 \mathrm{~mm}$ ) were formed on the inner surface of the tube by the fixed mandrel. The tube cross-section (area) before drawing, calculated from nominal dimensions, is $301.59 \mathrm{~mm}^{2}$. The nominal area after drawing was determined from the diameter of the die, the shape, and dimensions of the fixed mandrel (Fig. 3). After drawing, the cross-section (area) of the pipe was $250.15 \mathrm{~mm} 2$. Thus, the cross-section of the tube was reduced by $51.44 \mathrm{~mm} 2$. This is a crosssectional reduction of $17 \%$ compared to the original section.

\section{Outer surface geometry}

Macrogeometric (roundness and cylindricity) and microgeometric (surface roughness and waviness) parameters were measured on the outer surface. There are various devices for measuring of roundness. [10] Roundness and cylindricity were measured on a RONDCOM 60A (Accretech, Japan). The parameters for measurement and evaluation were as follows: Roundness measurement (on the outer surfaces):
- Number of measured points by roundness measurement: 3600 ,

- Method of roundness evaluation: MZC (The Minimum Zone Circle) [11, 12],

- The filter used to evaluate the roundness: Gauss low 50 UPR,

Cylindricity measurement (on the outer surfaces):

- Method of cylindricity measurement: crosssection method,

- Number of positions by cylindricity measurement: 11,

- Number of measured points by cylindricity measurement: 3600 x $11=39600$,

- Method of cylindricity evaluation: MZC (The Minimum Zone Circle) $[13,14]$,

- The filter used to evaluate the cylindricity: Gauss low 50 UPR,

- Measured length: $30 \mathrm{~mm}$.

The measured roundness values are given in Tab. 2. There are also shown the eccentricity values from the common axis measured on the individual roundness profiles. The lower part of the table shows the cylindricity values measured on the surfaces.

Tab. 2 Measured values [um]

\begin{tabular}{|c|c|c|c|c|c|c|c|c|}
\hline \multirow[b]{2}{*}{ P.n. } & \multicolumn{2}{|c|}{$\begin{array}{l}\text { Straight grooves - } \\
\text { reduction semi-an- } \\
\text { gle } 6^{\circ}\end{array}$} & \multicolumn{2}{|c|}{$\begin{array}{l}\text { Straight grooves - re- } \\
\text { duction semi-angle } \\
\qquad 12^{\circ}\end{array}$} & \multicolumn{2}{|c|}{$\begin{array}{l}\text { Spiral grooves - re- } \\
\text { duction semi-angle } \\
6^{\circ}\end{array}$} & \multicolumn{2}{|c|}{$\begin{array}{l}\text { Spiral grooves - re- } \\
\text { duction semi-angle } \\
12^{\circ}\end{array}$} \\
\hline & Roun. & Ecc. & Roun. & Ecc. & Roun. & Ecc. & Roun. & Ecc. \\
\hline 1 & 21.778 & 3.379 & 67.304 & 4.004 & 24.278 & 14.022 & 80.290 & 9.925 \\
\hline 2 & 23.778 & 1.072 & 67.798 & 1.567 & 23.165 & 6.535 & 79.543 & 7.347 \\
\hline 3 & 23.704 & 3.276 & 68.045 & 3.957 & 30.740 & 5.295 & 78.068 & 5.660 \\
\hline 4 & 22.788 & 3.884 & 68.220 & 4.405 & 40.467 & 4.710 & 85.730 & 5.639 \\
\hline 5 & 18.595 & 2.987 & 67.966 & 2.870 & 44.855 & 13.574 & 87.092 & 6.462 \\
\hline 6 & 17.232 & 3.607 & 69.093 & 2.683 & 43.129 & 17.284 & 84.674 & 12.262 \\
\hline 7 & 16.524 & 4.040 & 69.992 & 4.415 & 39.143 & 12.891 & 81.583 & 18.623 \\
\hline 8 & 17.433 & 4.139 & 71.564 & 3.981 & 33.041 & 12.964 & 81.527 & 15.215 \\
\hline 9 & 19.746 & 3.474 & 71.395 & 1.939 & 33.036 & 18.658 & 81.074 & 10.162 \\
\hline 10 & 20.772 & 2.024 & 69.623 & 0.706 & 24.980 & 15.349 & 78.423 & 7.484 \\
\hline 11 & 22.705 & 0.283 & 68.903 & 5.842 & 20.792 & 15.821 & 75.402 & 8.189 \\
\hline Aver. & 20.460 & 2.924 & 69.082 & 3.306 & 32.511 & 12.464 & 81.219 & 9.724 \\
\hline Cyl. & \multicolumn{2}{|c|}{27.517} & \multicolumn{2}{|c|}{79.307} & \multicolumn{2}{|c|}{54.464} & \multicolumn{2}{|c|}{91.949} \\
\hline
\end{tabular}

Comment:

P.n. - profile numberAver. - average Ecc. - eccentricity

Roun. - roundnessCyl. - cylindricity
The average roundness values are graphically presented together with the maximum and minimum values in fig. 4. The cylindricity values are also given. The average values eccentricity is shown together with the maximum and minimum measured values in fig. 5 . 


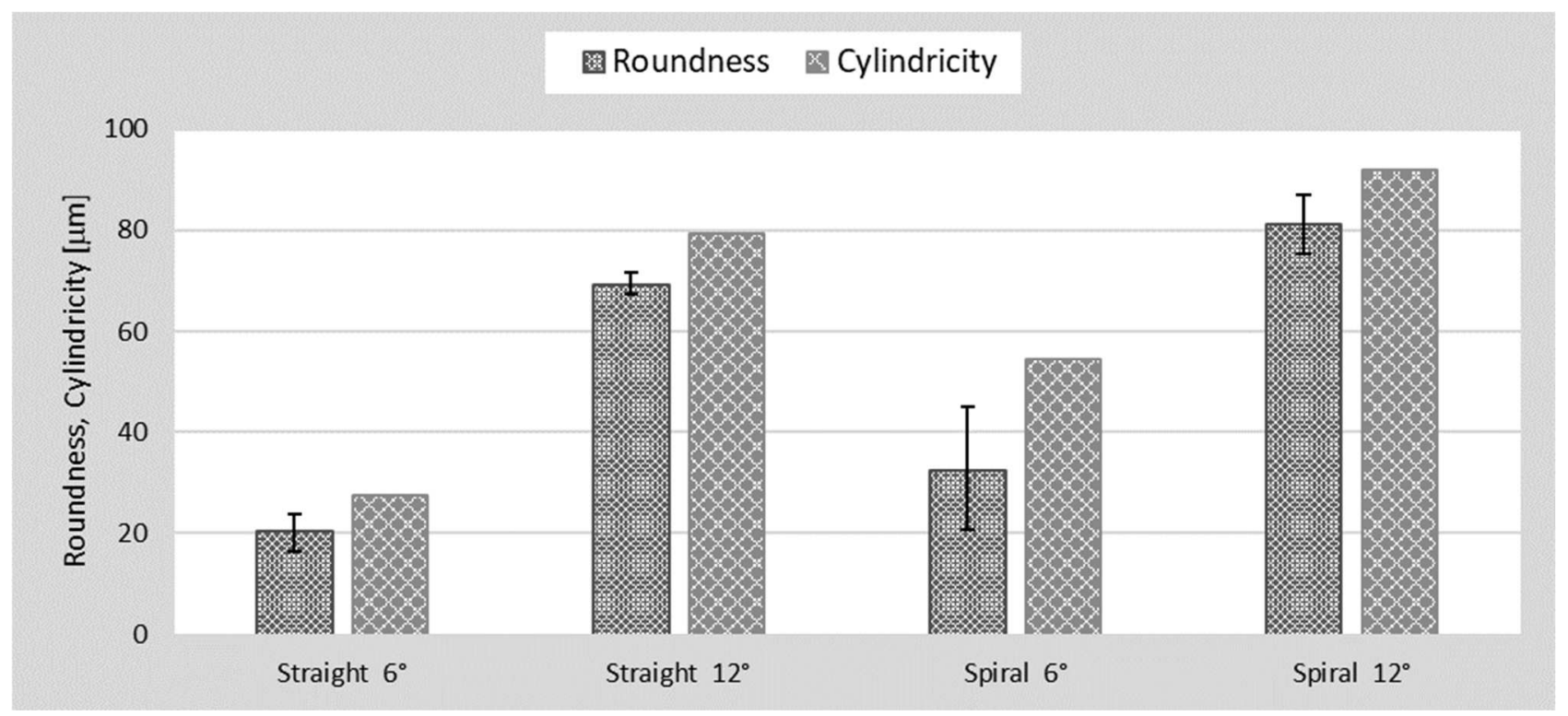

Fig. 4 Roundness and cylindricity values

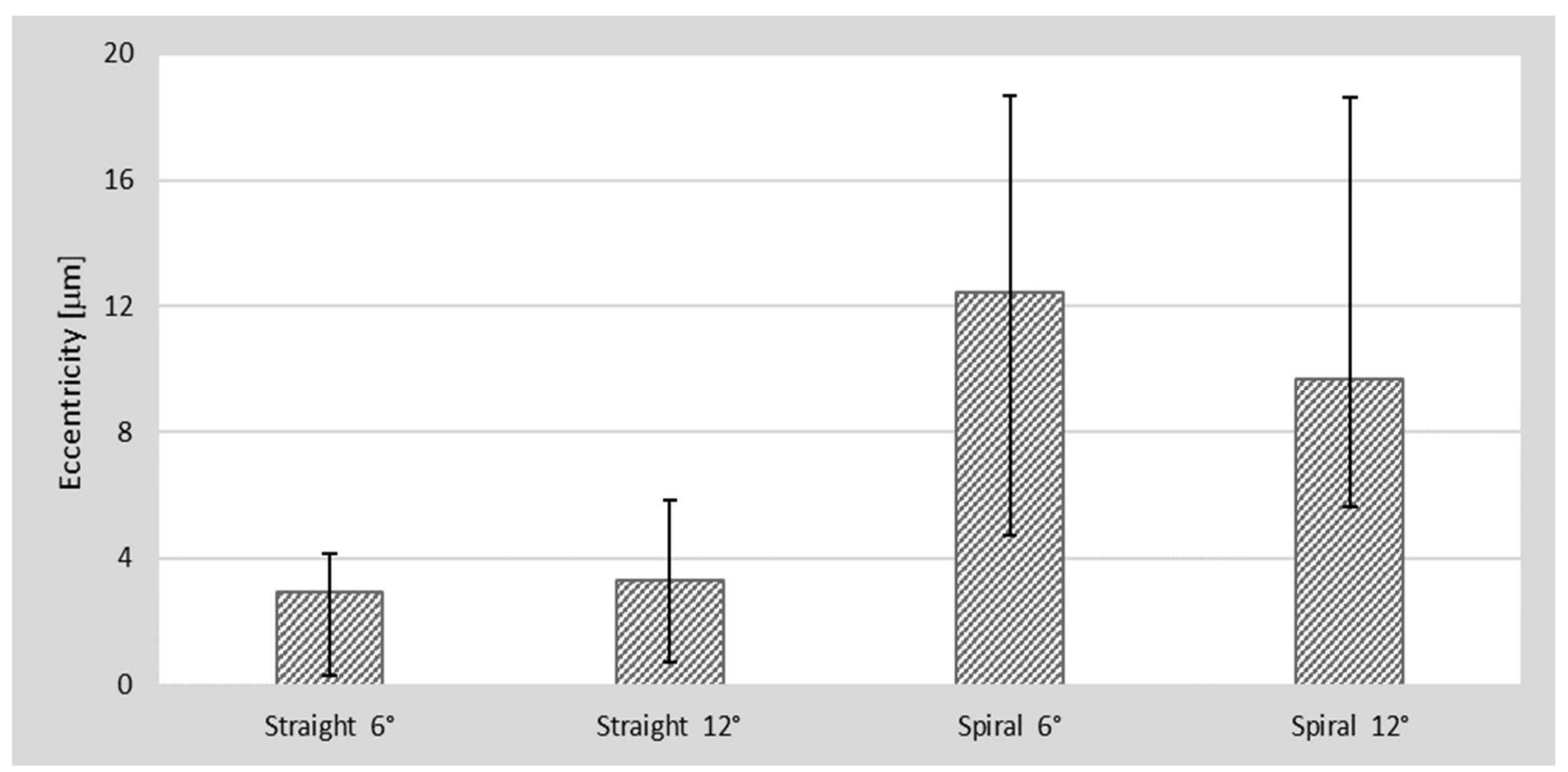

Fig. 5 Eccentricity values
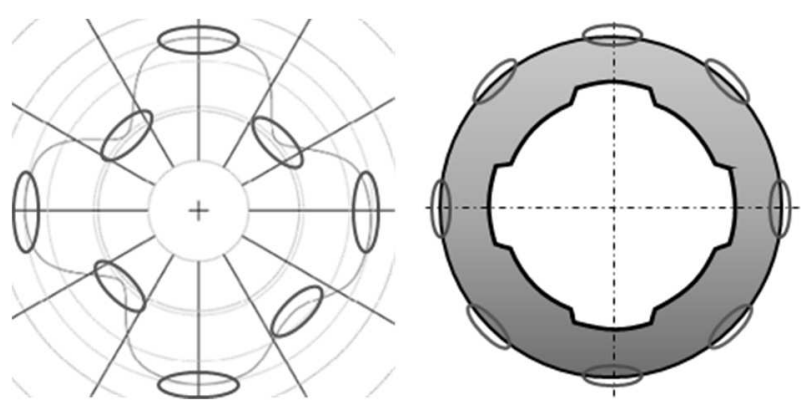

Fig. 6 Measured roundness profile and cross section of drawn tube with marked groves and lands

On the measured roundness profiles, where the lands (wall thickness of $4 \mathrm{~mm}$ ) and grooves (wall thickness of $3.5 \mathrm{~mm}$ ) were formed during drawing on the tube, are clearly observed. Although lands and grooves were formed on the inner surface of the tube, their production had an influence on the geometric parameters on the outer surface of the tube. Fig. 6 shows the measured profile on the outer surface of the drawn tube. There is the cross-section of the tube shows, too. On the outside surface of the tube, in places grooves, the profile identifies the "extrusion" of the material.

Fig. 7 shows the measured roundness profiles on the outer surfaces of the drawn tubes. Each figure shows 11 profiles. On tubes with straight grooves, the profiles overlap. On tubes with spiral grooves, the profiles are mutually rotated. The spiral grooves are rotated differently at different measurement places. All images have the same display scale. 

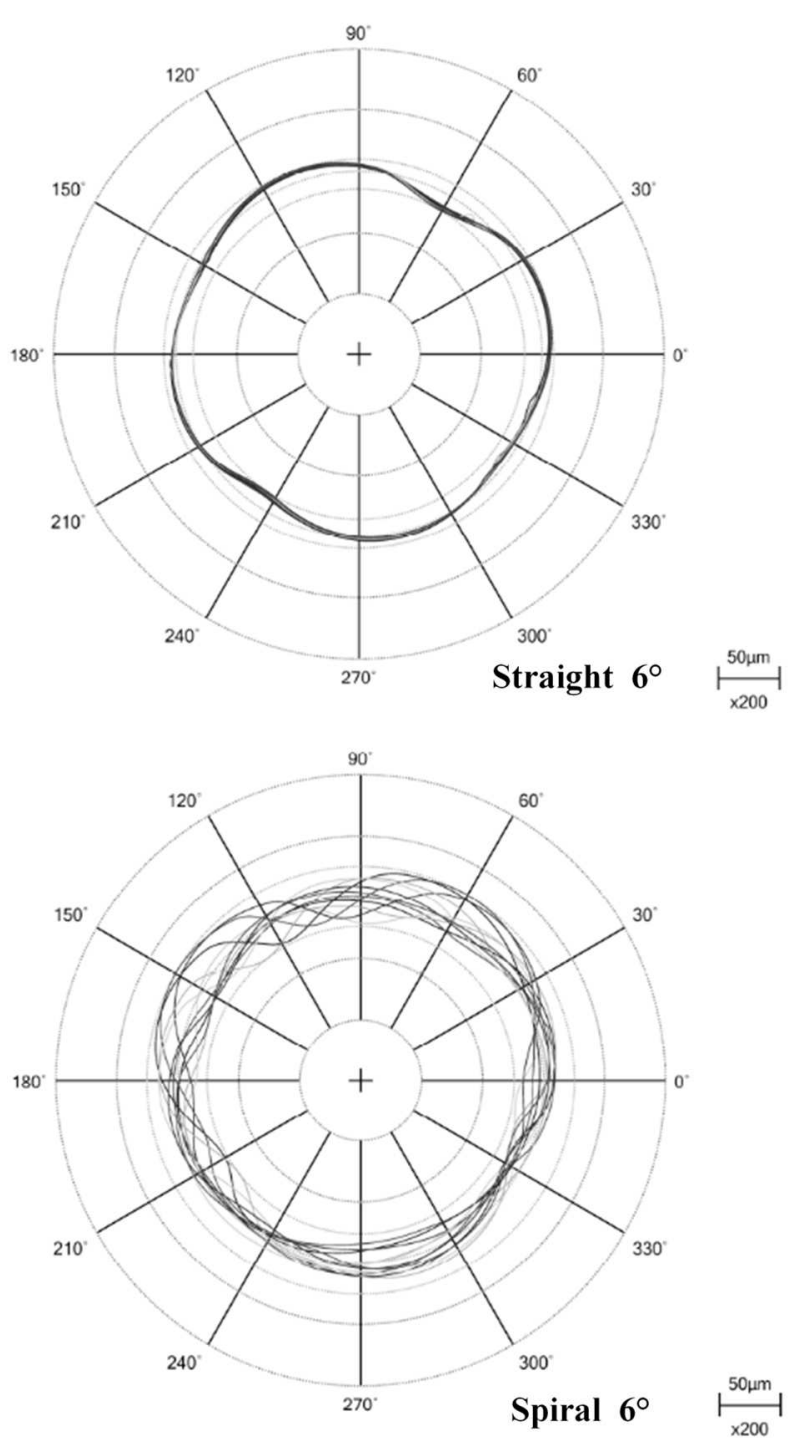
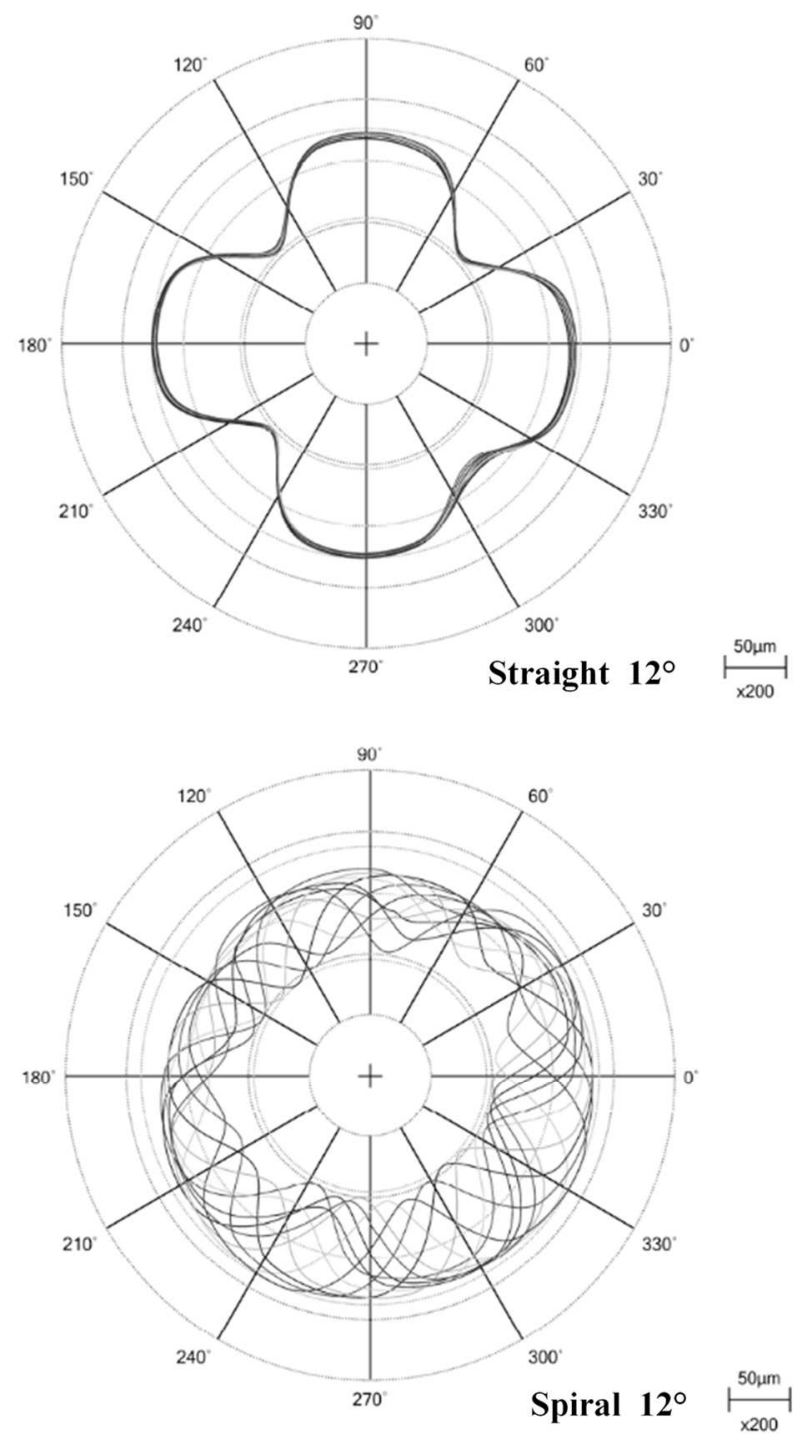

Fig. 7 Measured roundness profiles

Models of cylindrical surfaces, which are presented in Fig. 8, were created from the measured data. For each figure, the eccentricity (size and direction) of each circular section is also graphically displayed. The highest value of eccentricity is shown at the bottom of the figure.

During the visual control of the outside surface of the drawn tube, 'glossy' and 'matt' parts of the surface were identified. The measured surface roughness values are presented in Tab. 3 (arithmetic means of measured values are given). A Surfcom 5000 instrument
(Accretech, Japan) was used for measurement. The baseline length was $\mathrm{lr}=0.8 \mathrm{~mm}$ and the evaluated length was $\ln =4 \mathrm{~mm}$. One profile was measured over a length $\ln =12 \mathrm{~mm}$. This profile was measured at the grove position as shown in fig. 9. Glossy parts of the surface were in grooves - it can be seen lower surface roughness values and the less dissected profile. The matt parts of the surface were in the lands - it can be seen higher surface roughness values and the more dissected profile

Tab. 3 Average surface roughness values [um]

\begin{tabular}{|l|r|r|r|r|r|r|r|r|r|}
\hline & Straight $6^{\circ}$ & Straight $12^{\circ}$ & Spiral $6^{\circ}$ & Spiral $12^{\circ}$ & $\begin{array}{c}\text { Straight } \\
6^{\circ}\end{array}$ & Straight $12^{\circ}$ & Spiral $6^{\circ}$ & Spiral $^{\circ} 2^{\circ}$ \\
\hline $\mathbf{R a}$ & 0.497 & Lands & & & & Grooves \\
\hline $\mathbf{R z}$ & 7.581 & 6.527 & 0.318 & 0.409 & 0.136 & 0.116 & 0.078 & 0.119 \\
\hline $\mathbf{R t}$ & 10.686 & 9.226 & 8.084 & 4.654 & 3.329 & 2.608 & 1.898 & 2.413 \\
\hline
\end{tabular}




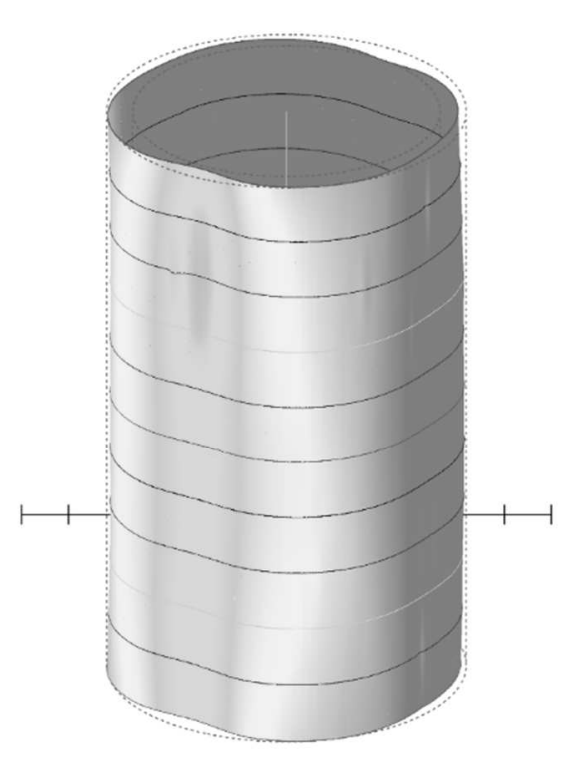

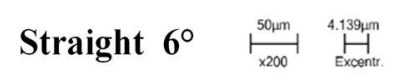

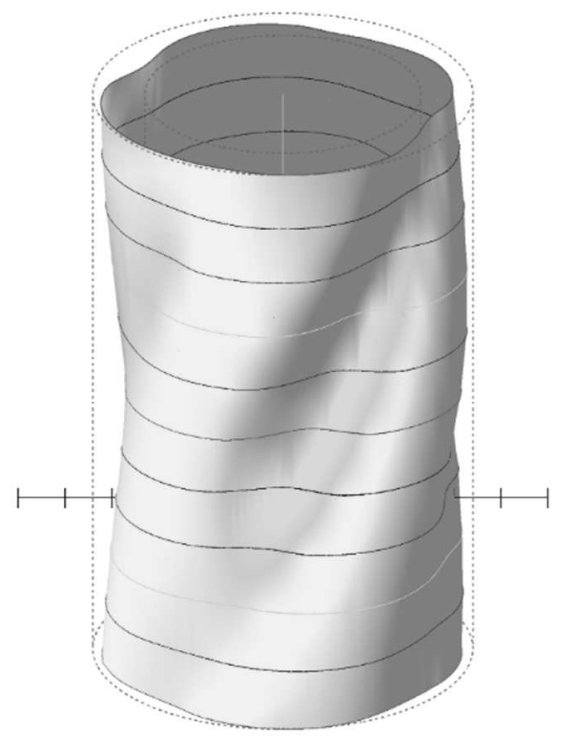

Spiral $6^{\circ}$
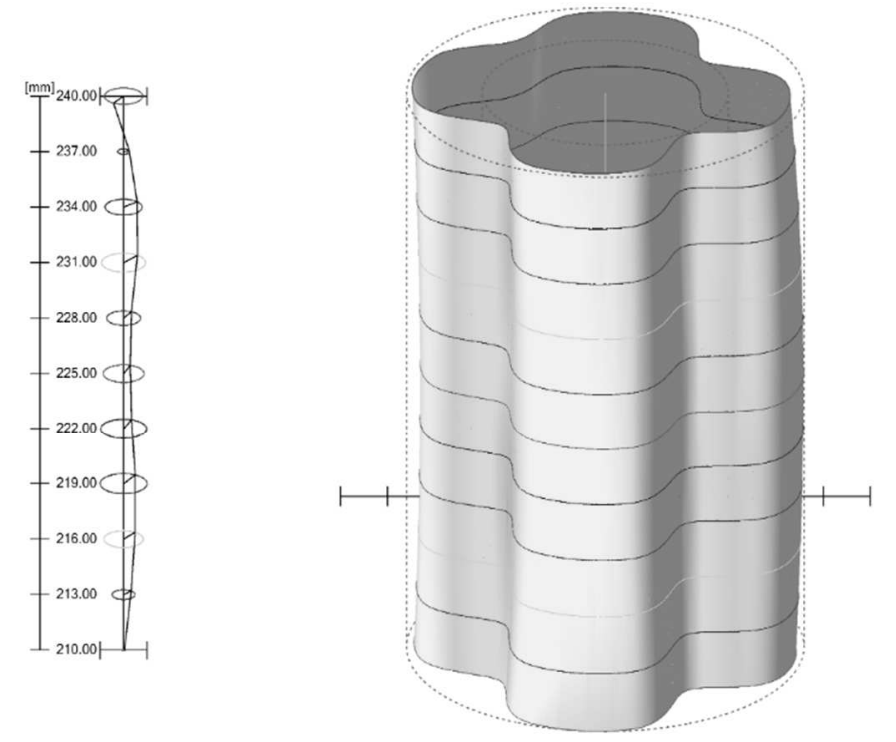

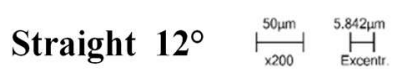
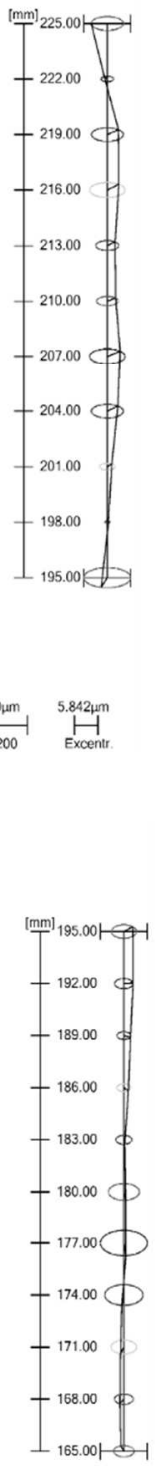

Fig. 8 Measured cylindrical surfaces
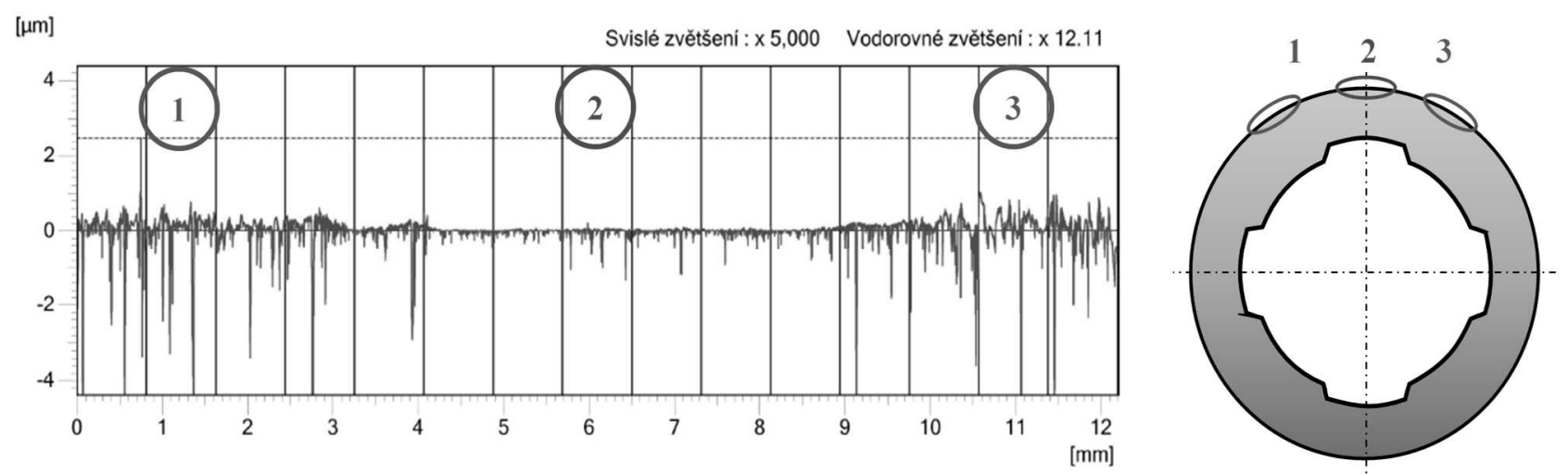

Fig. 9 Surface roughness profile

1,3-surface at the lands, 2- surface at the groove 


\section{Summary}

Based on conducted experiments and the achieved results, it is possible to acknowledge these arguments:

Visual evaluation of drawing surface

On the outer surface of the drawn tube, the grooves are visually glossy than in the lands.

\section{Macrogeometry after drawing}

The effect of the shape of the fixed mandrel is clearly visible on the roundness profiles.

In the grooves, the material is concave on the outer surface - the outside diameter of the drawn tube increases.

In the lands, the material is convex on the outer surface - the outside diameter of the drawn tube is reduced.

The roundness of the drawn tube is less for the die at $6^{\circ}$ than for the die at $12^{\circ}$. The average roundness increased by $250-337 \%$ at a die with a $12^{\circ}$.

The roundness of the drawn tube is less with a fixed mandrel with straight grooves than with a fixed mandrel with spiral grooves. The average roundness of fixed mandrel with a spiral groove increased by 117 $159 \%$.

The eccentricity was not significantly influenced by the die angle - sometimes went up slightly at the die with an angle of $12^{\circ}$, sometimes went down slightly.

The average eccentricity jumped dramatically by 294-426\% using spiral groove mandrel compared to straight groove mandrel.

The cylindricity of the drawn tube at the die with an angle of $6^{\circ}$ is less than at $12^{\circ}$ - it increased by 168 $288 \%$ at the die with an angle of $12{ }^{\circ}$.

The cylindricity of the drawn tube is less by the fixed mandrel with straight grooves than with spiral grooves - it has increased by $115-197 \%$ for spiral grooves.

\section{Microgeometry after drawing}

The effect of the shape of the fixed mandrel is also visible on the microgeometry of the surface (surface roughness). The surface roughness values ( $R a, R z$, and $\mathrm{Rt}$ ) are significantly lower at the grooves compared to the lands. In lands, the surface roughness profile is much more dissected compared to grooves.

\section{Final evaluation}

The shape of the fixed mandrel when drawing the tubes affects microgeometry, macro geometry and the visual effect of the outer surface of the drawn tube. In the measured surface roughness profiles, deep narrow depressions and low protrusions are dominant. It indicates that the surface is formed by lots of microcracks. There is a significant difference between lands and grooves - it is dominant in macro geometry. This is due to the different deformation of the material at these locations.

\section{Acknowledgement}

The Slovak Research and Development Agency supported this work under contracts APVV-150319 and $A P V V-18-0418$.

\section{References}

[1] KEJZLAR P, SEIBERT O, ANDRŠOVÁ Z, BURIK P. (2018) The Study of the Effect of Mechanical and Heat Treatment on the Crystal Texture of Cold Drawn Seamless Tubes. In: Manufacturing Technology. Vol.18(4):585-592. doi: 10.21062/ujep/142.2018/a/12132489/MT/18/4/585

[2] TANG, Y., DONG-SHENG, O., ZHENPING, W., LONG-SHENG, L., BIN, L. (2011). Influence of Drawing Process Parameters on Forming of Micro Copper Tube with Straight Grooves. In. Trans. Nonferrous Met. Soc. China, Vol. 21, pp. 2264-2269.

[3] KUBOKI, T., ISHIKAWA, M., KAJIKAWA, S., MURATA, M. (2018). An extrusion method of tube with spiral inner fins by utilizing generation of spiral outer fins/grooves. In: CIRP Annals - Manufacturing Technology, Vol. 67, No. 1, pp. 305-308.

[4] MURATA M., KUBOKI T., KOBAYASHI M., YAMAZAKI, H. (2012). Influence of Billet Material of Extruded Circular Tube with Spiral Projections on Inside Wall. In: Metal Forming, pp. 463-466. Krakow.

[5] GUNASEKERA, J. S., HOSHINO, S. (1982). Analysis of Extrusion or Drawing of Polygonal Sections through Straightly Converging Dies. In: Journal of Engineering for Industry, Vol. 104, pp. 38-45.

[6] NEVES, F. O., BUTTON, S. T., CAMINAGA, C., GENTILE, F. C. (2005). Numerical and Experimental Analysis of Tube Drawing with Fixed Plug. In: J. of the Braz: Soc. of Mech. Sci. \& Eng., Vol. 17, No. 4, pp. 426-431.

[7] YAGITA, T., KUBOKI, T., MURATA, M. (2014). Formability improvement by die-bearing grooves in tube extrusion with spiral inner projections. In: Procedia Engineering, Vol. 81, pp. $641-646$

[8] GÖRÖG, A., GÖRÖGOVÁ, I., MARTINKOVIČ, M. (2020). Analysis of the surface roughness of a tube drawn by a fixed mandrel. In: Novel Trends in Production Devices and Systems VI (NTPDS VI): Special topic volume with invited peer reviewed papers only. TTP. Zurich. 
[9] STN 41 1353. (1983). Steel 11 353. Bratislava: SUTN.

[10] VIT, J., NOVAK, M. (2018) A Roundness Machine Measuring Probe Calibration. In: Manufacturing Technology. Vol. 18(6):1053-1059. doi: 10.21062/ujep/223.2018/a/12132489/MT/18/6/1053.

[11] GÖRÖG, A., GÖRÖGOVÁ, I. (2018). Research of the influence of clamping forces on the roundness deviations of the pipes turned surface. In: Research papers Faculty of Materials Science and Technology Slovak. University of Technology in Trmava, Vol. 26, No. 42, pp. 47-54
[12] SUI, W., ZHANG, D. (2012). Four Methods for Roundness Evaluation. In: Physics Procedia, Vol. 24, pp. $2159-2164$.

[13] DEVILLERS, O., PREPARATA, F. P. (2000). Evaluating the cylindricity of a nominally cylindrical point set. In: Symposium on discrete algorithms, pp. 518-527.

[14] STANCEKOVA, D., MARTIKAN, P., SVOBODOVA, J., JANOTA, M., KRATOCHVIL, J. (2018) Influence of Cutting Parameters on Cylindricity Deviation by Centerless Grinding. In: Manufacturing Technology. Vol. 18(4):674-678. doi: 10.21062/ujep/159.2018/a/12132489/MT/18/4/674. 